\title{
Reformas regressivas e política de saúde
}

Desde a abertura do processo de impeachment da presidente Dilma Rousseff assistimos a um processo acelerado de aprofundamento de reformas regressivas ou contrarreformas das políticas públicas e sociais (BEHRING, 2008), em ataque frontal ao reformismo fraco (SINGER; LOUREIRO, 2016) praticado pelos governos petistas no executivo federal entre $2003 \mathrm{e}$ 2014. Este ataque das forças conservadoras aglutinadas em torno do governo de Michel Temer (MDB) em várias frentes, políticas e programas (novo regime fiscal, reforma trabalhista e previdenciária, reforma do ensino médio, intervenção das forças armadas na segurança pública) têm afetado com particular intensidade as políticas sociais de saúde e educação. Na política de saúde cortes de gastos em um quadro de subfinanciamento crônico, tem produzido mortes nas filas de espera por tratamento e aumento de epidemias (dengue e febre amarela como as mais notórias).

A política de saúde no Brasil, configurada no Sistema Único de Saúde, tem caráter universal, público e gratuito e pelas dimensões da população e cobertura do atendimento pode ser considerada uma das mais amplas do mundo, exigindo, portanto, um alto nível de intervenção e investimento do Estado para que o sistema possa funcionar satisfatoriamente.

Entretanto, desde a promulgação da constituição de 1988 e da aprovação da Lei Orgânica da Saúde, os defensores de uma política de saúde privada e concentrada no binômio saúdedoença, têm avançado sobre o SUS, impondo o subfinanciamento e formas variadas de privatização do sistema (terceirização da gestão, parcerias público-privadas, Empresa Brasileira de Serviços Hospitalares), impedindo, desde os anos 1990, que toda a estrutura pensada pelo movimento sanitarista brasileiro e incorporada às duas leis que regulam a política, pudesse se materializar de forma completa.

O modelo de política de saúde construído pelo movimento pela reforma sanitária foi forjado, desde os anos 1960, em um amplo movimento social que articulou trabalhadores, usuários e estudiosos. Fundamenta-se na compreensão de que o processo saúde-doença é resultante dos determinantes econômicos e sociais das condições de vida da população, a responsabilidade pela promoção da saúde, portanto, não é apenas individual, mas coletiva. A saúde não é um bem ou serviço que possa ser mercantilizado, mas um direito social e como tal deve ser assegurado por políticas sociais de provisão estatal. Este modelo articula-se a um projeto societário anticapitalista, combinando a provisão publica de serviços de saúde e ações de promoção da saúde a mudanças na gestão da política, democratizando-a, e na definição das prioridades estatais, colocando o atendimento às necessidades da população em primeiro lugar.

Por confrontar a necessidade de captura total do fundo público pelo capital, a política de saúde no Brasil e no mundo tem sido um alvo sistemático de propostas reformadoras de modo a transformá-la em bens e serviços a serem ofertados pelo mercado ou subsidiar a oferta pelo setor privado (filantrópico e lucrativo). No Brasil o confronto entre o modelo médico assistencial privatista e o modelo público e universal sanitarista, desenha-se desde os

Argum., Vitória, v. 10, n. 1, p. 4-8, jan./abr. 2018. 
anos 1960, aprofunda-se com as lutas pelo fim da ditadura militar nos anos 1970 e 1980 e ganha novos contornos nos anos 1990, quando após a aprovação da nova constituição e da Lei Orgânica da Saúde, a construção do SUS foi sistematicamente inviabilizada por sucessivos planos econômicos e reformas fiscais que priorizavam o pagamento dos juros da dívida e o equilíbrio fiscal. Simultaneamente, como resposta da burguesia à grande crise capitalista mundial iniciada nos anos 1970, avançam propostas de redução das intervenções sociais e econômicas do Estado em todo o mundo.

Para a política de saúde no Brasil esta redução da intervenção do Estado se caracterizou primeiro pela indefinição quanto ao percentual a ser gasto em saúde pela união, estados e municípios e, posteriormente, quando esta definição foi estabelecida com a Emenda Constitucional 29 (EC 29) em 2001, pela disputa quanto ao que poderia ser caracterizado como ações e serviços públicos de saúde, o que ocorreu apenas em $2012 \mathrm{com}$ a lei complementar 141, demonstrando o acirramento da disputa pelo fundo público para a política de saúde no país.

E embora a aprovação da EC 29 e da lei complementar 141 tenham contribuído para um aumento dos gastos do Estado com a política de saúde, a disputa e o debate em torno dos destinos dos recursos estatais continuam, pois união, estados e municípios não alocam na saúde recursos superiores ao mínimo definido pela emenda constitucional.

Com o novo regime fiscal (EC 95/2016) aprovado pelo governo de Michel Temer, o estrangulamento financeiro de todas as políticas sociais será completo e para a saúde, perverso, uma vez que estados e municípios não têm e não terão recursos para o combate a epidemias e endemias e para ampliação dos serviços em função do aumento populacional e das necessidades da população.

A EC 95, a EC do teto, limita o crescimento dos gastos do Estado com as despesas primárias ao montante aplicado no ano anterior corrigido pela taxa de inflação, reduzindo os gastos do Estado em proporção ao PIB. Para a saúde, uma vez que a PEC do teto entrará em vigor este ano, foi estabelecido que o mínimo a ser aplicado corresponderá a 15\% da Receita Corrente Líquida em 2017 corrigidos pela inflação. A partir de então, por 20 anos, o mínimo a ser aplicado pela união, estados e municípios ficará congelado, pois corresponderá aos $15 \%$ da $\operatorname{Re}$ ceita Corrente Líquida de 2017 corrigidos pela inflação do ano, mesmo que aumentos da Receita Corrente Líquida ou do PIB ocorram.

E tudo isso para que o Estado brasileiro continue a destinar mais de $40 \%$ de suas receitas para o pagamento de juros da dívida, alimentando o sistema financeiro internacional, além de manter elevados os subsídios estatais ao setor privado via terceirização e entrega dos equipamentos públicos de saúde para Organizações Sociais. Ou seja, atravessamos uma brutal reforma regressiva e antidemocrática do Estado, aprofundando de forma acelerada um processo de penalização dos pobres e trabalhadores que se estabeleceu desde os anos 1990, para que o capital possa se apropriar de todo o fundo público, até mesmo dos parcos recursos destinados à reprodução da força de trabalho no Brasil.

Neste sentido, o tema do presente número da revista Argumentum não poderia ser mais pertinente. $\mathrm{O}$ número de artigos recebidos e a qualidade dos mesmos demonstram uma grande

Argum., Vitória, v. 10, n. 1, p. 4-8, jan./abr. 2018. 
preocupação dos estudiosos no Brasil e na América Latina em entender esse momento e fornecer dados aos movimentos de resistência. Sob muitas e variadas formas, o estrangulamento financeiro da política de saúde e do SUS, a privatização sorrateira por meio dos chamados novos modelos de gestão, os confrontos e resistências entre os diferentes projetos em disputa na sociedade brasileira são abordados nos artigos da seção temática.

Em As contrarreformas na política de saúde do governo Temer - texto da seção Debate que inaugura este número -, Bravo, Pelaez e Pinheiro problematizam as ações de desmonte na saúde e colocam em evidência o abandono da concepção de reforma sanitária, e do próprio SUS. Chamam a atenção, ademais, para um estratégico direcionamento do Estado brasileiro em favor dos interesses do capital, em descompasso com os interesses da classe trabalhadora, colocando em xeque o caráter público e universal da saúde.

Para abrir a seção Artigos Temáticos, Andreia de Oliveira e Tânia Regina Kruger, analisam Os 30 anos da Constituição Federal e a participação popular no SUS a partir de um estudo bibliográfico e documental e de uma sistematizada participação em atividades promovidas pelos Conselhos e Conferências de Saúde. Ao longo do texto, as autoras buscam destacar os constantes desafios do processo de desconstitucionalização do SUS.

Nos artigos seguintes, Ana Cristina de Souza Vieira, em Política de saúde e HIV: Direito à saúde e reformas regressivas, expõe as consequências das reformas regressivas na saúde dos brasileiros e brasileiras que convivem com a Aids, limitando seu direito ao acesso à saúde; enquanto Joseane Barbosa de Lima, em A contrarreforma do sistema único de saúde: o caso das Organizações Sociais, mostra os percalços para a sustentação, qualificação e ampliação dos próprios serviços da saúde e o quanto esse setor tem sido um mercado lucrativo para o capital.

Em continuação, os dois próximos artigos, resultados de pesquisa bibliográfica e documental, abarcam diferentes níveis de complexidade no que tange aspectos de regulamentação e intervenção no campo da saúde. No primeiro, intitulado Judicialização da saúde: Aspectos legais e impactos orçamentários, Ivan Corrêa Leite analisa as implicações do aumento expressivo das decisões judiciais referentes às concessões de medicamentos para os usuários do SUS, no Estado de Mato Grosso do Sul. Os resultados de sua investigação levam-no a concluir que tais medidas têm ocasionado uma realocação de recursos, impactando diretamente no orçamento público brasileiro como um todo; A seguir, em $A$ inserção do assistente social na APS: reflexões a partir do Nasf, Débora Martini e Keli Regina Dal Prá,nos apresenta um panorama sobre a atividade do assistente social na Atenção Primária em Saúde (APS), a partir da criação dos Núcleos de Apoio à Saúde da Família (NASF). Ao longo do texto as autoras nos chamam a atenção para a precarização dos vínculos laborais dos profissionais que atuam nesses serviços.

Na sequência, o artigo intitulado Saúde de testemunhas protegidas na crise atual: um direito ameaçado, aborda uma temática pouco discutida e que também demanda atenção. O tema é problematizado por Danielle Galdino e Cristiano Guedes. A seguir, o trabalho Políticas de saúde no Mercosul: relevância e funcionalidade da dimensão jurídico-normativa, assinado pelas autoras Helenara Silveira Fagundes, Vera Maria Ribeiro Nogueira e Ineiva Terezinha Kreutz, propõe um debate acerca das regulações e acordos firmados entre os Estados Partes

Argum., Vitória, v. 10, n. 1, p. 4-8, jan./abr. 2018. 
no campo da proteção social em saúde e analisam de que forma tais acordos e normativas respondem aos residentes fronteiriços.

Também é tema desta edição o envelhecimento da população cubana e o impacto dessa realidade na política de saúde desse país. O aumento da expectativa de vida do povo cubano e as consequências em torno a essa questão incidem diretamente sobre a necessidade do cuidado para com a população idosa. O tema é discutido por Laura Galeano Zaldivar e Henry Colina Hernández no artigo Reflexiones en torno al cuidado en Cuba. Os autores colocam em evidência a "crisis del cuidado" nesse país e defendem a implementação de uma rede nacional voltada a oferecer esse serviço, como um direito garantido pelo Estado.Nos três trabalhos seguintes são discutidos aspectos igualmente necessários para enriquecer o debate sobre a política de saúde. Em Inovação tecnológica em saúde: o CAPS transformando o modelo assistencial, Estela Capelas Barbosa e Flávia Mendes de Oliveira destacam a importância da incorporação de novas tecnologias em saúde para a transformação das políticas públicas nesse campo, tendo como o foco do debate o Centro de Atenção Psicossocial (CAPS) pela Política Nacional de Saúde Mental; A seguir, no artigo intitulado Acolhimento na unidade de terapia intensiva neonatal: percepções das profissionais e mães, Aline Rodrigues da Silva, Edla Hoffmann, e Sabrina Silva Zacaroni defendem um atendimento humanizado, voltado para as mães e bebês hospitalizados nas unidades de Terapia Intensiva Neonatal. A pesquisa, de caráter qualitativo, se situa no contexto da Maternidade Escola Januário Cicco (UTIN/MEJC), no estado do Rio Grande do Norte; Na sequência, Janine Vieira Teixeira apresenta o artigo Trabalhadores estatutários e a Empresa Brasileira de Serviços Hospitalares, no qual descreve,a partir de um estudo qualitativo, o processo de implantação da Empresa no Hospital Universitário Cassiano Antônio Morais (Hucam) da Universidade Federal do Espírito Santo (Ufes). A autora analisa as consequências desse modelo de gestão na saúde dos trabalhadores e trabalhadoras.

Nesta edição também não poderíamos deixar de abordar uma das mais complexas problemáticas que impacta diretamente na vida dos usuários do SUS: a falta de leitos de UTI. Rodrigo de Souza Medeiros, em Insuficiência de leitos de UTI: crise do capital e mercantilização da saúde, destaca as mazelas e limitações que permeiam essa questão, explicitando os principais aspectos dessa grave carência que afeta a maioria da população brasileira.

Para fechar esta seção, a argentina Victoria Galoviche, em seu artigo Involucramiento masculino en Programa de Salud Sexual y Reproductiva de San Juan-Argentina, propõe uma abordagem das políticas de saúde sexual e reprodutiva desde um enfoque de gênero. Nesse contexto a autora defende a participação dos homens em uma saúde sexual e reprodutiva mais igualitária e reflete sobre a importância da compreensão das relações de poder entre os gêneros.

Os desafios lançados nas pesquisas aqui apresentadas denotam o compromisso e o trabalho coletivo dos (as) profissionais e estudiosos (as) que se dedicam ao campo da saúde no Brasil. De forma unânime, os autores (as) nos convocam à uma urgente restauração da luta em defesa do Sistema Único de Saúde assim como das propostas da Reforma Sanitária.

Gostaríamos de expressar o nosso agradecimento aos autores, autoras, pareceristas e a todos e todas que contribuíram para a realização e fechamento deste número.

Argum., Vitória, v. 10, n. 1, p. 4-8, jan./abr. 2018. 
Desejamos-lhe uma proveitosa leitura!

\section{REFERÊNCIAS}

BEHRING, Elaine Rosseti. Brasil em contrarreforma. São Paulo: Cortez, 2008.

SINGER, André; LOUREIRO, Isabel. (Orgs). As contradições do lulismo: a que ponto chegamos? São Paulo: Boitempo, 2016.

Ana Targina Rodrigues Ferraz e Franciani Bernardes 